\title{
Plasma micronutrient levels and telomere length in children
}

Running title: Micronutrient levels and telomere length in children

Authors: Elizabeth Milne, MPH PhD ${ }^{1}$, Nathan O’Callaghan, $\mathrm{PhD}^{2}$, Padmaja Ramankutty, $\mathrm{PhD}^{1}$, Nicholas H de Klerk, $\mathrm{PhD}^{1}$, Kathryn R Greenop, $\mathrm{PhD}^{1}$, Bruce K Armstrong, DPhil ${ }^{3,4}$, Margaret Miller, MAppSci, GradDipDiet ${ }^{5}$, Michael Fenech, $\mathrm{PhD}^{2}$

\section{Author Affiliations}

1. Telethon Kids Institute, University of Western Australia, Perth, Western Australia, Australia.

2. Commonwealth Scientific and Industrial Research Organization (CSIRO) Food, Nutrition and Bioproducts Flagship, Adelaide, South Australia, Australia.

3. Sydney School of Public Health, University of Sydney, New South Wales, Australia

4. Sax Institute, Sydney, New South Wales, Australia

5. Child Health Promotion Research Centre, Edith Cowan University, Perth, Western Australia, Australia.

\section{Author for correspondence:}

Elizabeth Milne.

Telethon Kids Institute

PO Box 855 WEST PERTH 6872 Western Australia

Telephone: + 61894897756

Fax: +61 894897700

Email: Liz.Milne@ telethonkids.org.au 
Disclosure of Conflict of Interest: None identified

\section{Abbreviations}

BMI: Body mass index

TL: Telomere length

MTHFR: Methylenetetrahydrofolate reducatase

RCF: Reduce folate carrier

MTR: 5-methyltetrahydrofolate-homocysteine methyltransferase

MTRR: 5-methyltetrahydrofolate-homocysteine methyltransferase reductase

XRCC1/3: X-ray repair cross-complementing protein $1 / 3$

GST: glutathione S-transferase

NAD, Nicotinamide adenine dinucleotide

NADP: nicotinamide adenine dinucleotide phosphate. 


\section{ABSTRACT (250 words)}

Objective

Telomeres are long hexamer (TTAGGG) repeats at the ends of chromosomes, and contribute to maintenance of chromosomal stability. Telomere shortening has been linked to cancers and other chronic diseases in adults, although evidence for causal associations is limited. Increasing evidence indicates that nutritional factors are associated with telomere length (TL) in adults, but there have been no studies of this association in children.

\section{Research Methods \& Procedures}

We conducted a cross-sectional study of nutritional factors and TL in 450 children between 2009 and 2011. Healthy children aged 3, 6 and 9 years provided blood samples, and their parents completed a food frequency questionnaire and a telephone interview about relevant environmental exposures. TL and blood micronutrient levels were measured, and genotyping at 10 loci was undertaken. Associations between the micronutrients and other variables were assessed using linear regression.

Results

No significant main or interactive effects of age or sex were seen. After adjustment for age, sex, parental education and month of blood collection, TL was inversely associated with plasma zinc, and shorter in children with the homozygous mutant genotype of the RFC G80A (rs 1051266) polymorphism.

\section{Conclusions}

This is the first investigation of associations between telomere length and micronutrients in healthy children.; an inverse association with zinc was seen.-The reason for the inverse relationship of TL with zinc is unknown but could be due to an increase in telomere sequence 
deletions caused by labile zinc-induced oxidative stress. These findings are consistent with those of previous in vitro studies, but should be corroborated in other studies before nutritional recommendations might be considered. Our data on TL in healthy children are a useful reference for other studies in the field.

Keywords: DNA damage, nutrients, nutrition, pediatric, polymorphisms, zinc 


\section{INTRODUCTION}

Telomeres are long hexamer (TTAGGG) repeats located at the ends of mammalian chromosomes that, together with the associated protein telosome structure, act to maintain chromosomal integrity and stability. However, telomeres shorten with age due to the incomplete replication of DNA at chromosome ends with each cell division and DNA strand breaks incurred by oxidative stress. Eventually telomeres shorten to the extent that they are unable to protect the ends of chromosomes from degradation, leading to accelerated cell senescence and death. Telomere degradation and/or dysfunction promote chromosomal instability via telomere end-fusion and the generation of breakage-fusion-bridge cycles within chromosomes $[1,2]$. These threats to genomic stability may result in abnormal karyotypes, altered gene dosage, loss of heterozygosity or gene amplification, which in turn cause abnormal gene expression including activation of oncogenes - or inactivation of tumour suppressor genes - important initiating events in carcinogenesis. Telomere shortening has been linked to several types of cancer (including lung, breast, colon, prostate and certain leukemias); these associations have been the subject of two recent meta-analyses [3, 4]. While most studies have been cross-sectional or retrospective, some prospective studies have found telomere shortening to be predictive of risk of cancer [5-7], adverse cardio-vascular events $[8,9]$ and mortality $[5,6,10,11]$.

There is increasing evidence that nutritional factors are associated with telomere length (TL) in adults. A recent longitudinal study reported an inverse relationship between marine omega-3 fatty acid levels in the blood and the rate of telomere attrition [12]. Other crosssectional studies have reported positive associations between TL and multivitamin use and dietary intake of vitamins $\mathrm{C}$ and $\mathrm{E}$ [13], folate [14, 15], vitamin D [16] and fibre [17]. In vitro studies have shown that age-related telomere shortening can be slowed by enrichment of 
intracellular vitamins C [18] and E [19]. Shorter telomeres have been associated with higher intake of processed meat [20] and alcohol [21], and higher body mass index (BMI) in adults $[22,23]$. There is also evidence that minerals involved in antioxidant response, such as zinc and selenium, may influence TL and telomere base damage, but the shape of the doseresponse relationship within the physiological range has yet to be determined [24-26].

Virtually all previous studies of factors associated with TL and other forms of DNA damage have been conducted in adults, and the focus of the few studies conducted in children to date has been on the effects of environmental pollutants and socioeconomic status $[27,28]$ rather than nutritional factors. Given that diseases of adulthood may originate early in life [29] and that lifelong dietary habits are established in childhood [30], it is important to examine whether nutrition during childhood is associated with telomere shortening. In this paper, we present the results of the first comprehensive study of blood micronutrient levels and TL in healthy children.

\section{MATERIALS AND METHODS}

A cross-sectional study of nutritional factors and DNA damage in children was conducted in Western Australia between 2009 and 2011. Parents of healthy children aged 3, 6 and 9 years were invited to participate through mail-outs to childcare centres and schools, and through community-based advertisements. Almost all volunteers were accepted into the study; only children with asthma, diabetes, cancer, arthritis or epilepsy were not eligible to take part. Parents of 464 children provided informed consent: 155 three-year olds, 155 six-year olds and 154 nine-year olds. The nine-year olds were also required to provide consent. The study was approved by the Department of Education and Training, and the University of Western Australia Human Research Ethics committee. 
Parents provided information about the family's demographics, the child's health, and relevant exposures in a telephone interview. Parents were mailed instructions about giving the child a simple breakfast on the day of the scheduled blood collection, and recording exactly what was eaten; toast, milk, butter, margarine and/or jam and water were allowed. Parents were also mailed a tube of anaesthetic cream to apply to the child's arm an hour before the appointment time. Height was measured in centimetres to one decimal point using a portable stadiometer (Seca, Medical Scales and Measuring systems, UK) and weight was measured in grams (to 100g) using a digital bathroom scale (HD-327, Tanita Corporation, Japan).

The phlebotomist collected $18 \mathrm{~mL}$ of blood on either one or two days. Blood samples were maintained at steady temperature $\left(5-10^{\circ} \mathrm{C}\right)$ in Labtop ${ }^{\circledR}$ coolers and couriered to the laboratory in insulated boxes (DGP BioTherm 25, Singapore); temperature during transportation was tracked with a digital thermometer placed with the samples. Approximately $1 \mathrm{~mL}$ of whole blood was used to measure vitamin B3 (niacin number) and red cell folate. The remaining blood was spun at $3000 \mathrm{rpm}$ for $20 \mathrm{~min}$ at $4^{\circ} \mathrm{C}$ and $3.8 \mathrm{~mL}$ of the plasma collected were used to measure folate, vitamins B12, and D, $\alpha$-tocopherol and carotenoids (lutein, retinol, lycopene, $\alpha$-carotene and $\beta$-carotene), and minerals (selenium, calcium, magnesium and zinc) levels. Red cell folate, plasma folate, and vitamin B12 were measured with a chemiluminescent microparticle folate or vitamin B12 binding protein assay, ARCHITECT ${ }^{\mathrm{TM}}$ (Abbott Laboratories, Abbott Park, IL, USA). Vitamin D was measured by an enzyme immunoassay before 2010 and an automated chemilumiescent assay after 2010 (both from Immuno Diagnostic Systems Ltd, Boldon, UK). Vitamin B3 (niacin number), was measured with a validated colorimetric enzymatic assay [31, 32]. $\alpha$-tocopherol and carotenoids (lutein, retinol, lycopene, $\alpha$-carotene and $\beta$-carotene) were measured by HPLC, and minerals were assessed by ICP-MS (calcium, magnesium and zinc) and ICP-OES (selenium). Peripheral 
blood lymphocytes (PBL) were isolated using Ficoll-paque ${ }^{\mathrm{TM}}$ Plus separation medium (Pharmacia Biotech, Uppsala, Sweden), prepared for cryopreservation in fetal bovine serum (FBS) plus $10 \%$ DMSO, frozen and stored at $-80^{\circ} \mathrm{C}$ until required. DNA was isolated from peripheral whole blood mononuclear cells using a QIAGEN DNeasy Kit with minor modifications to prevent DNA oxidation, as described by Lu et al. [33]. Absolute TL was measured in duplicate samples by determining the number of TTAGGG hexamer repeats using quantitative real-time PCR (qPCR) as described by O'Callaghan et al. [34]. TL values in kb/diploid genome were calculated using a synthesised TTAGGG 84mer oligonucleotide to generate a standard curve; the number of diploid genome copies per reaction was determined using the single copy gene $36 B 4$. If the results for duplicate samples differed by more than one Cq value, the results were discarded and the assay repeated. Using our internal control (1301 cell line DNA) we estimated that the inter-experimental variability was $\leq 7 \%$ $(\mathrm{n}=55)$ and the intra-experimental variability $1.1 \%(\mathrm{n}=34)$.

Genotyping was performed at the following loci according to standard protocols: MTHFR C677T (rs 1801133), MTHFR A1298C (rs 1801131), MTR A2756G (rs 1805087), MTRR A66G (rs 1801394), OGG1 Ser326Cys (rs 1052134), XRCC1 Arg399Gln (rs 25487), RFC G80A (rs 1051266), GST Mu, GST Theta, and XRCC3 Thr241Met (rs 861539). These loci were chosen because they had previously been shown to be associated with chromosome instability [35, 36], but only MTHFR C677T had been previously investigated in relation to TL (in adults) [14]. MTHFR, MTR, MTRR and RFC enzymes are required for bioavailability and metabolism of folate and vitamin B12, and the chosen polymorphisms are known to reduce the activity of these enzymes $[37,38]$. Thus, genotype may impact the availability of folate for DNA synthesis/repair and SAM for maintenance of DNA methylation, which are essential for genome and telomere integrity [35, 39]. The MTHFR enzyme is required for the conversion of the 5,10 methylenetetrahydrofolate, the folate form required for thymidine 
synthesis, to 5-methyltetrahydrofolate, the folate form required for conversion of homocysteine to methionine from which the common methyl donor S-adenosyl methinionine (SAM) is synthesised[40]. Synthesis of methionine is catalysed by MTR, which requires vitamin B12 as cofactor in its reduced form which is maintained in this state by the activity of the MTRR enzyme [41]. In addition entry of 5-methyltetrahydrofolate from plasma and interstitial fluids into cells occurs through the activity of RFC, the reduced folate carrier [42]. XRCC1 and XRCC3 are required for the repair of DNA base lesions and DNA single and double strand breaks caused by oxidative stress which lead to telomere dysfunction and attrition [36, 43]. GST Mu and GST Theta are enzymes required for detoxification of genotoxic chemicals by catalysing conjugation with reduced glutathione [39, 44]. The polymorphisms we studied for the XRCC and GST genes involve mutations that reduce the activity of their protein products $[39,43,44]$.

\section{Statistical analysis}

The following variables were considered as possible predictors of TL: blood micronutrient levels, supplement use, child's BMI z-score, parents' ages at the child's birth, socioeconomic status (parental education, household income), ethnicity, blood cortisol and cotinine levels, environmental exposures (x-rays, immunizations, pesticide exposure, history of fevers, medication use, sunburn, parental smoking), and genotype. We aimed to identify the smallest subset of these variables that still had good predictive ability for TL using multivariate linear regression. Analyses were conducted in SPSS 22 (IBM SPSS Statistics for Windows, Version 22.0. Armonk, NY: IBM Corp).

As TL is potentially related to age, sex and month of blood collection, these variables were entered into all models. All nutrient, demographic, environmental and genotype variables were then added one at a time to assess the relationship with TL. Nutrient variables with a univariate $P$-value $\leq 0.10$ were assessed for inclusion in a combined model, and for 
interactions with genotypes. Genotype main effects or interactions that indicated larger or smaller effect sizes for heterozygotes than both wild-type and variant homozygotes were excluded. All variables or interactions of interest were then added to a combined model and retained if the variable block caused a significant change in R-squared, or (for ordinal variables and bi-allelic genotypes), had a significant trend $P$-value of the coefficient.

\section{RESULTS}

Data on blood micronutrient levels and TL were available for 464 children. The age and sex distribution of these children is shown in Table 1, along with other anthropometric and demographic measures of interest. Most children were in the normal height, weight and healthy BMI ranges for age. The distribution of household income and parental education was higher than in the general Australian population; 53\% of study children lived in households with an annual income $>\$ 100,000$, compared with $13 \%$ of Australian households with children [45]; and $71 \%$ of children had at least one parent with a tertiary education, compared with $43 \%$ of Australian adults [46].

Table 1: Descriptive statistics of participants

\begin{tabular}{lllll}
\hline Age group & 3-year olds & 6-year olds & 9-year olds & All \\
\hline $\mathrm{N}$ & 155 & 155 & 154 & 464 \\
$\mathrm{~N}$ with TL data & 146 & 147 & 144 & 437 \\
$\mathrm{~N}(\%)$ boys & $75(48.4)$ & $86(55.5)$ & $73(47.4)$ & $234(50.0)$ \\
Weight: Mean (SD) (kg) & $16.1(2.0)$ & $23.2(3.7)$ & $33.2(6.9)$ & $24.2(8.4)$ \\
Height: Mean (SD) (cm) & $99.9(4.3)$ & $121.2(5.2)$ & $137.9(8.0)$ & $119.7(16.7)$ \\
\hline
\end{tabular}




\begin{tabular}{|c|c|c|c|c|}
\hline BMI: Mean (SD) $\left(\mathrm{kg} / \mathrm{m}^{2}\right)$ & $16.1(1.2)$ & $15.7(1.7)$ & $17.4(3.7)$ & $16.41(2.6)$ \\
\hline BMI z-score: Mean (SD) & $-0.39(0.73)$ & $-0.29(1.14)$ & $-0.17(1.27)$ & $-0.28(1.07)$ \\
\hline Cotinine Mean (SD) (ng/ml) & $0.81(0.99)$ & $0.59(0.75)$ & $0.64(0.44)$ & $0.68(0.76)$ \\
\hline Cortisol Mean (SD) (ug/dl) & $0.38(0.22)$ & $0.34(0.20)$ & $0.33(0.18)$ & $0.35(0.20)$ \\
\hline $\mathrm{N}(\%)$ child ethnicity European & $120(77.4)$ & $120(77.4)$ & $118(76.6)$ & $358(77.2)$ \\
\hline \multicolumn{5}{|l|}{$\mathrm{N}(\%)$ child ethnicity at least } \\
\hline $50 \%$ European & $18(11.6)$ & $15(9.7)$ & $19(12.3)$ & $52(11.2)$ \\
\hline \multicolumn{5}{|l|}{$\mathrm{N}(\%)$ child ethnicity at least } \\
\hline $50 \%$ non-European & $13(8.4)$ & 18 (11.6) & $13(8.4)$ & $44(9.5)$ \\
\hline \multicolumn{5}{|l|}{$\mathrm{N}(\%)$ child ethnicity } \\
\hline indeterminate & $4(2.6)$ & $2(1.3)$ & $4(2.6)$ & $10(2.2)$ \\
\hline \multicolumn{5}{|l|}{$\mathrm{N} \%$ Parental education some } \\
\hline high school & $6(3.9)$ & $8(5.2)$ & $9(5.8)$ & $23(5.0)$ \\
\hline \multicolumn{5}{|l|}{$\mathrm{N}(\%)$ Parental education } \\
\hline complete high school & $5(3.2)$ & $13(8.4)$ & $17(11.0)$ & $35(7.5)$ \\
\hline \multicolumn{5}{|l|}{ N (\%) Parental education trade } \\
\hline or technical qualification & $22(14.2)$ & $31(20.0)$ & $25(16.2)$ & $78(16.8)$ \\
\hline \multicolumn{5}{|l|}{ N (\%) Parental education } \\
\hline university/college & $122(78.7)$ & $103(66.5)$ & $103(66.9)$ & $328(70.7)$ \\
\hline \multicolumn{5}{|l|}{$\mathrm{N}(\%)$ household income up to } \\
\hline$\$ 20,000 \mathrm{pa}$ & $2(1.3)$ & $7(4.5)$ & $5(3.2)$ & $14(3.0)$ \\
\hline $\mathrm{N}(\%)$ household income & $13(8.4)$ & $19(12.3)$ & $22(14.3)$ & $54(11.7)$ \\
\hline
\end{tabular}




\begin{tabular}{|c|c|c|c|c|}
\hline \multicolumn{5}{|l|}{$\$ 20,001$ to $\$ 50,000 \mathrm{pa}$} \\
\hline \multicolumn{5}{|l|}{$\mathrm{N}(\%)$ household income } \\
\hline$\$ 50,001$ to $\$ 100,000 \mathrm{pa}$ & $52(33.8)$ & $51(32.9)$ & $48(31.2)$ & $151(32.6)$ \\
\hline \multicolumn{5}{|l|}{$\mathrm{N}(\%)$ household income } \\
\hline$\$ 100,001$ to $\$ 150,000 \mathrm{pa}$ & $54(35.1)$ & $43(27.7)$ & $38(24.7)$ & $135(29.2)$ \\
\hline \multicolumn{5}{|l|}{$\mathrm{N}(\%)$ household income over } \\
\hline$\$ 150,000$ & $33(21.4)$ & $35(22.6)$ & $41(26.6)$ & $109(23.5)$ \\
\hline $\mathrm{N}(\%)$ Child had X-ray ${ }^{\mathrm{a}}$ & $9(5.8)$ & $10(6.5)$ & $17(11.0)$ & $36(7.8)$ \\
\hline $\mathrm{N}(\%)$ Child had medications ${ }^{\mathrm{a}}$ & $123(79.4)$ & $122(78.7)$ & $111(72.1)$ & $356(76.7)$ \\
\hline \multicolumn{5}{|l|}{ N(\%) Professional pesticide } \\
\hline control in the house $\mathrm{e}^{\mathrm{a}}$ & $10(6.5)$ & $17(11.0)$ & $18(11.7)$ & $45(9.7)$ \\
\hline $\mathrm{N}(\%)$ Child had immunization ${ }^{\mathrm{a}}$ & $30(19.4)$ & $8(5.2)$ & $4(2.6)$ & $42(9.1)$ \\
\hline $\mathrm{N}(\%)$ Child had a fever ${ }^{\mathrm{a}}$ & $67(43.2)$ & $47(30.3)$ & $44(28.6)$ & $158(34.1)$ \\
\hline $\mathrm{N}(\%)$ Child got sunburnt ${ }^{\mathrm{a}}$ & $3(2.0)$ & $8(5.1)$ & $14(9.1 \%)$ & $25(5.4)$ \\
\hline Mean (SD) mothers age & $32.2(4.9)$ & $31.1(5.0)$ & $30.7(5.5)$ & $31.3(5.1)$ \\
\hline Mean (SD) fathers age & $34.9(5.9)$ & $33.2(6.0)$ & $33.4(6.7)$ & $33.8(6.3)$ \\
\hline $\mathrm{N}(\%)$ Mother smoked $^{\mathrm{a}}$ & $11(7.1)$ & $13(8.4)$ & $16(10.4)$ & $40(8.6)$ \\
\hline $\mathrm{N}(\%)$ Father smoked ${ }^{\mathrm{a}}$ & $20(13.3)$ & $20(13.2)$ & $29(19.0)$ & $69(15.2)$ \\
\hline
\end{tabular}

${ }^{\mathrm{a}}$ In the 4 months before the interview. 
Mean values for each of the 16 blood micronutrients investigated varied little by sex or age group (Table 2). Likewise, raw mean values for TL were similar across sexes and age groups. 
Table 2: Mean (SD) telomere length and blood micronutrient levels by sex and age

\begin{tabular}{|c|c|c|c|c|c|c|c|c|c|c|c|c|}
\hline \multirow{2}{*}{$\begin{array}{l}\text { Micronutrient } \\
\text { Telomere length (kb/diploid genome) }\end{array}$} & \multirow{2}{*}{\begin{tabular}{|l|} 
boys \\
292.9
\end{tabular}} & \multirow[b]{2}{*}{ (89.6) } & \multicolumn{2}{|l|}{ girls } & \multicolumn{2}{|c|}{ 3-year olds } & \multicolumn{2}{|c|}{ 6-year olds } & \multicolumn{2}{|c|}{ 9-year olds } & \multicolumn{2}{|c|}{ Overall } \\
\hline & & & 294.8 & $(84.0)$ & 299.8 & $(90.8)$ & 289.1 & (83.4) & 292.5 & (86.3) & 293.8 & $(86.8)$ \\
\hline Zinc $(\mu \mathrm{mol} / \mathrm{L})$ & 14.4 & (1.9) & 14.7 & (1.7) & 13.9 & $(1.7)$ & 14.8 & $(1.9)$ & 15.0 & (1.6) & 14.6 & (1.8) \\
\hline Calcium, total (mmol/L) & 2.3 & $(0.2)$ & 2.3 & $(0.1)$ & 2.3 & $(0.2)$ & 2.3 & $(0.1)$ & 2.3 & $(0.1)$ & 2.3 & $(0.1)$ \\
\hline Magnesium (mmol/L) & 0.8 & $(0.1)$ & 0.8 & $(0.1)$ & 0.8 & $(0.1)$ & 0.8 & $(0.1)$ & 0.8 & $(0.1)$ & 0.8 & $(0.1)$ \\
\hline Calcium/Magnesium ratio & 2.9 & $(0.2)$ & 2.9 & $(0.2)$ & 2.9 & $(0.2)$ & 2.9 & $(0.2)$ & 2.9 & $(0.2)$ & 2.9 & $(0.2)$ \\
\hline Vitamin B12 (pmol/L) & 534.7 & $(208.8)$ & 554.6 & $(226.7)$ & 585.8 & $(258.6)$ & 548.6 & $(197.2)$ & 499.6 & $(183.2)$ & 544.6 & $(217.9)$ \\
\hline Plasma Folate (nmol/L) & 36.7 & $(6.8)$ & 36.6 & $(7.9)$ & 38.7 & $(6.0)$ & 36.7 & $(7.4)$ & 34.4 & (7.8) & 36.6 & (7.3) \\
\hline Red Cell Folate (nmol/L) & 830.1 & $(267.3)$ & 777.7 & $(294.5)$ & 828.2 & $(276.3)$ & 827.3 & $(293.4)$ & 756.9 & $(272.6)$ & 803.8 & $(282.2)$ \\
\hline Vitamin D (nmol/L) & 91.4 & $(29.1)$ & 85.5 & $(34.4)$ & 82.1 & $(25.5)$ & 92.4 & $(35.6)$ & 90.8 & $(33.1)$ & 88.5 & $(32.0)$ \\
\hline Selenium $(\mu \mathrm{mol} / \mathrm{L})$ & 1.1 & $(0.1)$ & 1.1 & $(0.1)$ & 1.1 & $(0.1)$ & 1.1 & $(0.1)$ & 1.1 & $(0.1)$ & 1.1 & $(0.1)$ \\
\hline Niacin Number (NAD/NADP*100) & 173.1 & $(27.2)$ & 181.8 & $(30.9)$ & 182.6 & $(28.0)$ & 175.7 & $(30.4)$ & 173.5 & $(29.6)$ & 177.6 & $(29.5)$ \\
\hline Lutein $(\mu \mathrm{mol} / \mathrm{L})$ & 0.4 & $(0.2)$ & 0.5 & $(0.3)$ & 0.4 & $(0.2)$ & 0.5 & $(0.2)$ & 0.5 & $(0.3)$ & 0.4 & $(0.3)$ \\
\hline Retinol $(\mu \mathrm{mol} / \mathrm{L})$ & 1.1 & $(0.2)$ & 1.2 & $(0.2)$ & 1.2 & $(0.2)$ & 1.1 & $(0.3)$ & 1.2 & $(0.2)$ & 1.2 & $(0.2)$ \\
\hline$\alpha$-tocopherol $(\mu \mathrm{mol} / \mathrm{L})$ & 23.1 & $(11.8)$ & 24.2 & $(12.6)$ & 19.9 & $(9.4)$ & 25.1 & $(12.5)$ & 25.9 & $(13.5)$ & 23.7 & $(12.2)$ \\
\hline
\end{tabular}




\begin{tabular}{|c|c|c|c|c|c|c|c|c|c|c|c|c|}
\hline Lycopene $(\mu \mathrm{mol} / \mathrm{L})$ & 0.5 & $(0.3)$ & 0.5 & $(0.3)$ & 0.4 & $(0.2)$ & 0.6 & $(0.3)$ & 0.6 & $(0.4)$ & 0.5 & $(0.3)$ \\
\hline$\alpha$-Carotene $(\mu \mathrm{mol} / \mathrm{L})$ & 193.8 & $(155.5)$ & 198.1 & $(164.3)$ & 163.8 & (129.6) & 210.2 & $(180.0)$ & 213.6 & $(161.8)$ & 195.9 & $(159.8)$ \\
\hline$\beta$-Carotene $(\mu \mathrm{mol} / \mathrm{L})$ & 0.5 & $(0.3)$ & 0.6 & $(0.4)$ & 0.5 & $(0.3)$ & 0.6 & $(0.4)$ & 0.6 & $(0.4)$ & 0.6 & $(0.4)$ \\
\hline
\end{tabular}


Genotype frequencies for the group as a whole are shown in Supplemental Table 1.

The coefficients of all variables tested for inclusion in the model (with only child's age, sex and month of blood collection also in the model) are shown in Supplemental Table 2. TL was found to be best modelled, in terms of both fit and prediction accuracy, by a linear function of the variables shown in Table 3. Shorter TL was associated with higher plasma zinc (Figure 1), higher parental education and the AA genotype of the RFC G80A polymorphism. A one-standard deviation increase in blood zinc levels was associated with a $11 \mathrm{~kb}$ /diploid genome decrease in TL, while the RFC 80AA genotype was associated with a $26 \mathrm{~kb} /$ diploid genome decrease relative to RFC 80GG genotype. No significant interactions between zinc and child's age or sex were seen.

Table 3: Regression coefficients for prediction of telomere length

\begin{tabular}{lllc}
\hline Term: & Estimate & $95 \% \mathrm{CI}$ & $P$ value \\
\hline Male & 0 & & \\
Female & 1.72 & $-15.13,18.56$ & 0.84 \\
Age 3 & 0 & & \\
Age 6 & -5.59 & $-26.75,15.57$ & 0.60 \\
Age 9 & -1.91 & $-23.44,19.61$ & 0.86 \\
Month of blood collection & -1.75 & $-5.08,1.59$ & 0.30 \\
Plasma zinc ( $\mu$ mol/L) & -6.07 & $-1.11,-1.03$ & 0.02 \\
Highest parental education some high school & 0 & & \\
Highest parental education complete high school & -11.93 & $-60.16,36.30$ & 0.63 \\
Highest parental education trade certificate & -37.12 & $-79.29,5.06$ & 0.08 \\
Highest parental education university/college & -35.93 & $-74.46,2.60$ & 0.07 \\
\hline
\end{tabular}




\begin{tabular}{llcc}
\hline$R F C 80 G G$ & 0 & & \\
$R F C 80 G A$ & -13.76 & $-32.04,4.51$ & 0.14 \\
$R F C 80 A A$ & -25.70 & $-50.67,-0.74$ & 0.04 \\
\hline
\end{tabular}

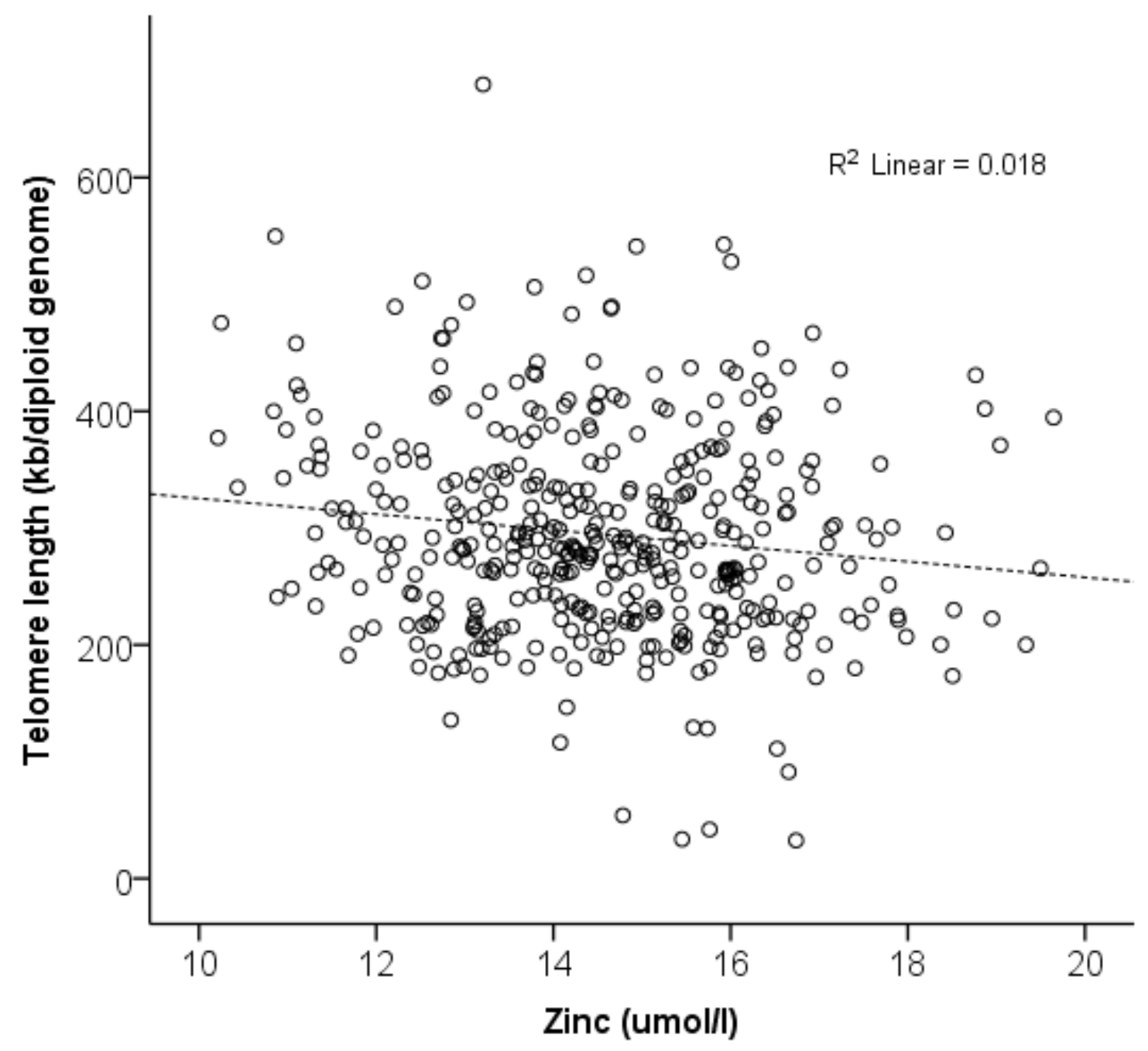

Figure 1: Scatterplot of telomere length by plasma zinc level.

DISCUSSION 
We have presented results for average blood micronutrient levels and TL in lymphocytes among healthy children aged 3,6 and 9 years. The results of our multivariable analyses indicated that TL in children was inversely associated with plasma zinc, and shorter in those with the AA genotype for the RFC G80A polymorphism.

Although the association between zinc and TL has been little explored, alteration in zinc homeostasis has been associated with diseases in which telomere shortening is a key characteristic [47-49]. Several studies suggest that zinc deficiency and excess may both be associated with adverse health outcomes $[26,50]$.

Two recent in vitro studies, in human lymphoblastoid and keratinocyte cells showed that biomarkers of chromosomal damage and DNA strand breaks tended to be lowest between 4 and 16 $\mu \mathrm{mol} / \mathrm{L}$ zinc, and significantly increased when zinc was deficient; further analysis of TL and base damage in the telomere sequence in this study showed that TL was shorter as zinc concentration increased and that base damage within the telomere was minimised at $4 \mu \mathrm{mol} / \mathrm{L}$ zinc concentration [25] (and unpublished observations). The mechanisms by which increases in zinc concentration may cause telomere shortening are unknown, but could include terminal deletions of chromosomes caused as a result of DNA strand breaks induced in the subtelomere or telomere sequence by reactive oxygen species generated by free labile zinc $[26,51,52]$.

The observation that TL was shorter in those with the AA (compared to GG) genotype of the RFC G80A (rs 1051266) polymorphism is of interest because carriage of the A allele is associated with reduced uptake of 5-methyltetrahydrofolate that potentially could render cells prone to folate deficiency $(39,40)$. Our in vitro studies showed that chronic low folate conditions over several weeks can result in telomere attrition and increased frequency of chromosomal instability biomarkers such as micronuclei, an indicator of chromosome breakage or loss [53]. 
In our study, TL was shorter among children of parents with higher education; the reason for this is not clear. The only other study of this association we identified was conducted in the US and involved 70 white and black US children aged 7-13; it showed that children with at least one collegeeducated parent had longer telomeres than those whose parents never attended college [28]. This association and inconsistencies between studies warrants further investigation.

Our study is the first to report TL, and to investigate the association between nutrition and TL, among healthy young children. While our findings are consistent with associations seen in adult studies and with known biological pathways, they remain speculative and need to be corroborated. It is possible, for example, that the association we observed between TL and plasma zinc concentration is due to confounding by an unmeasured factor.

The study has strengths and limitations. Blood samples were collected and transported to the laboratory under tightly controlled conditions, and TL was measured using state of the art methods; between-person agreement of TL was high. Biochemical measures of a wide range of micronutrients were available, which precluded the need for reliance on parent recall of children's nutritional intake. The measurement of multiple micronutrients and other factors, and their comprehensive assessment for inclusion in our regression models, enabled us to take account of the possible contributions of a range of individual factors and their interactions.

This novel study was cross-sectional and exploratory in nature, and prospective follow-up of participants would be required to establish causal associations. The recruited families were of relatively high socioeconomic status, and their nutritional status was generally good, so our findings may not be generalizable to the wider population. However, there is noevidence to suggest that the associations we observed would not also occur in children from lower socioeconomic status backgrounds. 
Investigation into possible associations between TL and various disease outcomes is ongoing, and it is highly probable that factors involved in TL maintenance and other relevant processes make an additional contribution to the determination of disease risk. Thus, although nutritional factors may have an effect on TL, their ultimate impact on disease outcomes through these pathways are currently speculative. Nonetheless, the association we observed between plasma zinc and TL in children provides further insight into the important role that nutritional factors play in telomere maintenance and genome integrity. Our findings are novel and require corroboration in other studies before any nutritional recommendations might be considered.

\section{ACKNOWLEDGEMENTS}

The authors would like to acknowledge the study coordinators: Meg McHugh, Sandy Costanzo and Wendy Chan She Ping-Delfos. Theodora Almond and Carolyn Salisbury (both CSIRO) are acknowledged for assisting with blood sample fractionation and storage for micronutrient analyses. Vanessa Russell is thanked and acknowledged for her role in performing the plasma carotenoid analyses

\section{Grant Support}

This work was funded by the Australian National Health and Medical Research Council (NH\&MRC, Project Grant \# 572623). 


\section{References}

[1] Callen E, Surralles J. Telomere dysfunction in genome instability syndromes. Mutat Res 2004; 567:85-104.doi: 10.1016/j.mrrev.2004.06.003

[2] Hande MP, Samper E, Lansdorp P, Blasco MA. Telomere length dynamics and chromosomal instability in cells derived from telomerase null mice. J Cell Biol 1999; 144:589-601.doi: 10.1083/jcb.144.4.589

[3] Wentzensen IM, Mirabello L, Pfeiffer RM, Savage SA. The association of telomere length and cancer: a meta-analysis. Cancer Epidemiol Biomarkers Prev 2011; 20:1238-50.doi: 10.1158/10559965.EPI-11-0005

[4] Ma H, Zhou Z, Wei S, Liu Z, Pooley KA, Dunning AM et al. Shortened telomere length is associated with increased risk of cancer: a meta-analysis. PLoS One 2011; 6:e20466.doi: 10.1371/journal.pone.0020466

[5] Willeit P, Willeit J, Mayr A, Weger S, Oberhollenzer F, Brandstatter A et al. Telomere length and risk of incident cancer and cancer mortality. JAMA 2010; 304:69-75.doi: 10.1001/jama.2010.897 [6] Willeit P, Willeit J, Kloss-Brandstatter A, Kronenberg F, Kiechl S. Fifteen-Year Follow-up of Association Between Telomere Length and Incident Cancer and Cancer Mortality. JAMA 2011; 306:42-4.doi: 10.1001/jama.2011.901

[7] McGrath M, Wong JY, Michaud D, Hunter DJ, De Vivo I. Telomere length, cigarette smoking, and bladder cancer risk in men and women. Cancer Epidemiol Biomarkers Prev 2007; 16:815-9.doi: 10.1158/1055-9965.EPI-06-0961

[8] Zee RY, Michaud SE, Germer S, Ridker PM. Association of shorter mean telomere length with risk of incident myocardial infarction: a prospective, nested case-control approach. Clin Chim Acta 2009; 403:139-41.doi: 10.1016/j.cca.2009.02.004

[9] Weischer M, Bojesen SE, Cawthon RM, Freiberg JJ, Tybjaerg-Hansen A, Nordestgaard BG. Short telomere length, myocardial infarction, ischemic heart disease, and early death. Arterioscler Thromb Vasc Biol 2012; 32:822-9.doi: 10.1161/ATVBAHA.111.237271

[10] Cawthon RM, Smith KR, O'Brien E, Sivatchenko A, Kerber RA. Association between telomere length in blood and mortality in people aged 60 years or older. Lancet 2003; 361:393-5.doi: 10.1016/S0140-6736(03)12384-7 
[11] Weischer M, Nordestgaard BG, Cawthon RM, Freiberg JJ, Tybjaerg-Hansen A, Bojesen SE. Short telomere length, cancer survival, and cancer risk in 47102 individuals. J Natl Cancer Inst 2013; 105:459-68.doi: 10.1093/jnci/djt016 djt016 [pii]

[12] Farzaneh-Far R, Lin J, Epel ES, Harris WS, Blackburn EH, Whooley MA. Association of marine omega-3 fatty acid levels with telomeric aging in patients with coronary heart disease. JAMA 2010; 303:250-7.doi: 10.1001/jama.2009.2008

[13] Xu Q, Parks CG, Deroo LA, Cawthon RM, Sandler DP, Chen HL. Multivitamin use and telomere length in women. Am J Clin Nutr 2009; 89:1857-63.doi: 10.3945/ajen.2008.26986

[14] Paul L, Cattaneo M, D'Angelo A, Sampietro F, Fermo I, Razzari C et al. Telomere length in peripheral blood mononuclear cells is associated with folate status in men. J Nutr 2009; 139:12738.doi: 10.3945/jn.109.104984

[15] Bull CF, O'Callaghan NJ, Mayrhofer G, Fenech MF. Telomere length in lymphocytes of older South Australian men may be inversely associated with plasma homocysteine. Rejuv Res 2009; 12:341-9.doi: 10.1089/rej.2009.0868

[16] Richards JB, Valdes AM, Gardner JP, Paximadas D, Kimura M, Nessa A et al. Higher serum vitamin D concentrations are associated with longer leukocyte telomere length in women. Am J Clin Nutr 2007; 86:1420-5

[17] Cassidy A, De Vivo I, Liu Y, Han J, Prescott J, Hunter DJ et al. Associations between diet, lifestyle factors, and telomere length in women. Am J Clin Nutr 2010; 91:1273-80.doi: 10.3945/ajen.2009.28947

[18] Furumoto K, Inoue E, Nagao N, Hiyama E, Miwa N. Age-dependent telomere shortening is slowed down by enrichment of intracellular vitamin C via suppression of oxidative stress. Life Sci 1998; 63:935-48.doi: 10.1016/S0024-3205(98)00351-8

[19] Tanaka Y, Moritoh Y, Miwa N. Age-dependent telomere-shortening is repressed by phosphorylated alpha-tocopherol together with cellular longevity and intracellular oxidative-stress reduction in human brain microvascular endotheliocytes. J Cell Biochem 2007; 102:689-703.doi: 10.1002/jcb.21322

[20] Nettleton JA, Diez-Roux A, Jenny NS, Fitzpatrick AL, Jacobs DR, Jr. Dietary patterns, food groups, and telomere length in the Multi-Ethnic Study of Atherosclerosis (MESA). Am J Clin Nutr 2008; 88:1405-12.doi: 10.3945/ajcn.2008.26429

[21] Pavanello S, Hoxha M, Dioni L, Bertazzi PA, Snenghi R, Nalesso A et al. Shortened telomeres in individuals with abuse in alcohol consumption. Int J Cancer 2011; 129:983-92.doi: 10.1002/ijc.25999 
[22] Njajou OT, Cawthon RM, Blackburn EH, Harris TB, Li R, Sanders JL et al. Shorter telomeres are associated with obesity and weight gain in the elderly. Int J Obes 2012; 36:1176-9.doi:

10.1038/ijo.2011.196

[23] O'Callaghan NJ, Clifton PM, Noakes M, Fenech M. Weight Loss in Obese Men Is Associated with Increased Telomere Length and Decreased Abasic Sites in Rectal Mucosa. Rejuv Res 2009; 12:169-76.doi: 10.1089/rej.2008.0819

[24] Ferguson LR, Karunasinghe N, Zhu S, Wang AH. Selenium and its' role in the maintenance of genomic stability. Mutat Res-Fundam Mol Mech Mutagen 2012.doi: 10.1016/j.mrfmmm.2011.12.011 [25] O'Callaghan N, Baack N, Sharif R, Fenech M. A qPCR-based assay to quantify oxidized guanine and other FPG-sensitive base lesions within telomeric DNA. Biotechniques 2011; 51:403-12.doi: $10.2144 / 000113788$

[26] Sharif R, Thomas P, Zalewski P, Fenech M. The role of zinc in genomic stability. Mutat ResFundam Mol Mech Mutagen 2012; 733:111-21.doi: 10.1016/j.mrfmmm.2011.08.009

[27] Kananen L, Surakka I, Pirkola S, Suvisaari J, Lönnqvist J, Peltonen L et al. Childhood adversities are associated with shorter telomere length at adult age both in individuals with an anxiety disorder and controls. PLoS One 2010; 5:e10826.doi: 10.1371/journal.pone.0010826

[28] Needham BL, Fernandez JR, Lin J, Epel ES, Blackburn EH. Socioeconomic status and cell aging in children. Soc Sci Med 2012; 74:1948-51.doi: 10.1016/j.socscimed.2012.02.019

[29] Forrest CB, Riley AW. Childhood origins of adult health: A basis for life-course health policy. Health Aff 2004; 23:155-64.doi: 10.1377/hlthaff.23.5.155

[30] Nicklaus S, Boggio V, Chabanet C, Issanchou S. A prospective study of food variety seeking in childhood, adolescence and early adult life. Appetite 2005; 44:289-97.doi:

10.1016/j.appet.2005.01.006

[31] Creeke PI, Dibari F, Cheung E, van den Briel T, Kyroussis E, Seal AJ. Whole blood NAD and NADP concentrations are not depressed in subjects with clinical pellagra. J Nutr 2007; 137:20137.doi: $137 / 9 / 2013$

[32] Jacobson EL, Jacobson MK. Tissue NAD as a biochemical measure of niacin status in humans. Methods Enzymol 1997; 280:221-30.doi: S0076-6879(97)80113-9

[33] Lu T, Pan Y, Kao SY, Li C, Kohane I, Chan J et al. Gene regulation and DNA damage in the ageing human brain. Nature 2004; 429:883-91.doi: 10.1038/nature02661

[34] O'Callaghan N, Dhillon V, Thomas P, Fenech M. A quantitative real-time PCR method for absolute telomere length. Biotechniques 2008; 44:807-9.doi: 10.2144/000112761 
[35] Botto N, Andreassi MG, Manfredi S, Masetti S, Cocci F, Colombo MG et al. Genetic polymorphisms in folate and homocysteine metabolism as risk factors for DNA damage. Eur J Hum Genet 2003; 11:671-8.doi: 10.1038/sj.ejhg.5201024

[36] Helleday T, Petermann E, Lundin C, Hodgson B, Sharma RA. DNA repair pathways as targets for cancer therapy. Nat Rev Cancer 2008; 8:193-204.doi: 10.1038/nrc2342

[37] Frosst P, Blom HJ, Milos R, Goyette P, Sheppard CA, Matthews RG et al. A candidate genetic risk factor for vascular disease: a common mutation in methylenetetrahydrofolate reductase. Nat Genet 1995; 10:111-3.doi: 10.1038/ng0595-111

[38] Weisberg I, Tran P, Christensen B, Sibani S, Rozen R. A second genetic polymorphism in methylenetetrahydrofolate reductase (MTHFR) associated with decreased enzyme activity. Mol Genet Metab 1998; 64:169-72.doi: 10.1006/mgme.1998.2714

[39] Dhillon VS, Thomas P, Iarmarcovai G, Kirsch-Volders M, Bonassi S, Fenech M. Genetic polymorphisms of genes involved in DNA repair and metabolism influence micronucleus frequencies in human peripheral blood lymphocytes. Mutagenesis 2011; 26:33-42.doi: 10.1093/mutage/geq076 [40] Fenech M. Folate (vitamin B9) and vitamin B12 and their function in the maintenance of nuclear and mitochondrial genome integrity. Mutat Res 2012; 733:21-33.doi: 10.1016/j.mrfmmm.2011.11.003 [41] Sharp L, Little J. Polymorphisms in genes involved in folate metabolism and colorectal neoplasia: A HuGE review. Am J Epidemiol 2004; 159:423-43.doi: 10.1093/aje/kwh066 [42] Matherly LH, Hou Z, Deng Y. Human reduced folate carrier: translation of basic biology to cancer etiology and therapy. Cancer Metastasis Rev 2007; 26:111-28.doi: 10.1007/s10555-007-90462

[43] Dhillon VS, Yeoh E, Fenech M. DNA repair gene polymorphisms and prostate cancer risk in South Australia--results of a pilot study. Urol Oncol 2011; 29:641-6.doi:

10.1016/j.urolonc.2009.08.013

[44] Chen L, Guo H, Yuan J, He M, Chen D, Shi J et al. Polymorphisms of GSTT1 and GSTM1 and increased micronucleus frequencies in peripheral blood lymphocytes in residents at an e-waste dismantling site in China. J Environ Sci Health A Tox Hazard Subst Environ Eng 2010; 45:490-7.doi: $10.1080 / 10934520903539366$

[45] Australian Bureau of Statistics. 'Australia, Basic Community Profile: B26 Gross Family Income (Weekly) by Family Composition'.

http://www.censusdata.abs.gov.au/AUSSTATS/2006Census4.nsf/logByLookupView?openagent\&200 10\%2DBCP\%2DAustralia\%2Ezip\&20060\&Main\%20Features\&02006\%20Census\%20Basic\%20Com 
munity\%20Profile\%20and\%20Snapshot27/11/071\&0\&2006\&27\%2E11\%2E2007\&Latest. Accessed 07 May 2012

[46] Australian Bureau of Statistics. 'Australia, Basic Community Profile: B39 Non-School Qualification: Level of Education by Age by Sex'.

http://www.censusdata.abs.gov.au/AUSSTATS/2006Census4.nsf/logByLookupView?openagent\&200 10\%2DBCP\%2DAustralia\%2Ezip\&20060\&Main\%20Features\&02006\%20Census\%20Basic\%20Com munity\%20Profile\%20and\%20Snapshot27/11/071\&0\&2006\&27\%2E11\%2E2007\&Latest. Accessed 07 May 2012

[47] Alsafwah S, Laguardia SP, Arroyo M, Dockery BK, Bhattacharya SK, Ahokas RA et al. Congestive heart failure is a systemic illness: a role for minerals and micronutrients. Clin Med Res 2007; 5:238-43.doi: 10.3121/cmr.2007.737

[48] Bostrom F, Hansson O, Gerhardsson L, Lundh T, Minthon L, Stomrud E et al. CSF Mg and Ca as diagnostic markers for dementia with Lewy bodies. Neurobiol Aging 2009; 30:1265-71.doi: 10.1016/j.neurobiolaging.2007.10.018

[49] Mahabir S, Forman MR, Dong YQ, Park Y, Hollenbeck A, Schatzkin A. Mineral intake and lung cancer risk in the NIH-American Association of Retired Persons Diet and Health study. Cancer Epidemiol Biomarkers Prev 2010; 19:1976-83.doi: 10.1158/1055-9965.EPI-10-0067

[50] Szewczyk B. Zinc homeostasis and neurodegenerative disorders. Front in Aging Neurosci 2013; 5:33.doi: 10.3389/fnagi.2013.00033

[51] Ayton S, Lei P, Bush AI. Metallostasis in Alzheimer's disease. Free Radic Biol Med 2013; 62:7689.doi: 10.1016/j.freeradbiomed.2012.10.558

[52] Hao Q, Maret W. Imbalance between pro-oxidant and pro-antioxidant functions of zinc in disease. J Alzheimers Dis 2005; 8:161-70; discussion 209-15

[53] Bull CF, Mayrhofer G, O'Callaghan NJ, Au AY, Pickett HA, Low GK et al. Folate deficiency induces dysfunctional long and short telomeres; both states are associated with hypomethylation and DNA damage in human WIL2-NS cells. Cancer Prev Res 2014; 7:128-38.doi: 10.1158/19406207.CAPR-13-0264 